Technical Report

\title{
Modeling quasi-static and high strain rate deformation and failure behavior of a $( \pm 45)$ symmetric E-glass/polyester composite under compressive loading
}

\author{
A. Kara, A. Tasdemirci*, M. Guden \\ Dynamic Testing and Modeling Laboratory and Department of Mechanical Engineering, Izmir Institute of Technology, Gulbahce, Urla, Izmir 35430, Turkey
}

\section{A R T I C L E I N F O}

\section{Article history:}

Received 7 August 2012

Accepted 2 January 2013

Available online 23 January 2013

\begin{abstract}
A B S T R A C T
Quasi-static $\left(1 \times 10^{-3}-1 \times 10^{-2} \mathrm{~s}^{-1}\right)$ and high strain rate $\left(\sim 1000 \mathrm{~s}^{-1}\right)$ compressive mechanical response and fracture/failure of a $( \pm 45)$ symmetric E-glass/polyester composite along three perpendicular directions were determined experimentally and numerically. A numerical model in LS-DYNA 971 using material model MAT_162 was developed to investigate the compression deformation and fracture of the composite at quasi-static and high strain rates. The compressive stress-strain behaviors of the composite along three directions were found strain rate sensitive. The modulus and maximum stress of the composite increased with increasing strain rate, while the strain rate sensitivity in in-plane direction was higher than that in through-thickness direction. The damage progression determined by high speed camera in the specimens well agreed with that of numerical model. The numerical model successfully predicted the damage initiation and progression as well as the failure modes of the composite.
\end{abstract}

(c) 2013 Elsevier Ltd. All rights reserved.

\section{Introduction}

Polymer matrix composites have been increasingly used in airplanes, spacecraft, light weight structures, medical prosthesis and sandwich structures. In these applications, the deformation rate in composites structures may exceed the quasi-static strain rate range particularly under high velocity impact loading. Hydraulic driven and/or drop weight impact test systems are widely used to test composites at intermediate strain rate levels, ranging from $50 \mathrm{~s}^{-1}$ to $150 \mathrm{~s}^{-1}$. On the other hand, the Split Hopkinson Pressure Bar (SHPB) is frequently used, in the testing of composite materials, to achieve the strain rates higher than $200-300 \mathrm{~s}^{-1}$. The SHPB testing can suffice nearly the uniaxial stress state and also be used as a tool to validate the determined constitutive relations. The compressive dynamic behavior of various composites has been previously investigated [1-5] using hydraulic testing machines (strain rates up to $\sim 100 \mathrm{~s}^{-1}$ ) and the SHPB apparatus for higher strain rates (strain rates of $500-2000 \mathrm{~s}^{-1}$ ). These studies were mainly focused on the determination of damage modes and strain rate sensitivity of composites experimentally. Gary and Zhao [6] investigated the compressive impact loading of polymer matrix composites using a so-called anti buckling device to prevent undesirable modes of composite buckling. Several studies also focused on the high strain rate tensile testing of the composites [7-9], using a tension SHPB apparatus and high speed tensile testing machine in the range of $\sim 100-1000 \mathrm{~s}^{-1}$. The strain rate dependent strength of the composites was reported to vary with the testing direction and the fracture mode of the

\footnotetext{
* Corresponding author. Tel.: +90 232 7506780; fax: +90 2327506701 .

E-mail address: alpertasdemirci@iyte.edu.tr (A. Tasdemirci).
}

composites was shown to be affected by the strain rate. Few studies were on the modeling the compression, tension and shear deformation of composites at high and quasi-static strain rates [10-12]. In these studies, the specimens recovered through interrupted tests were examined microscopically in order to explore the differences in the sequences of damage initiation between quasi-static and high strain rate loadings. The effect of sample size on the measured mechanical properties of the composites was also analyzed numerically. The quasi-static and high strain rate behavior of glass fiber reinforced polymer composites were previously investigated experimentally and numerically [13-15] and Brown et al. [16] simulated the deformation of the thermoplastic composites using material model MAT_162 in LS-DYNA 971.

The present study is an extension of the modeling efforts, simply to incorporate the material deformation and failure models together to determine both deformation and fracture of the composite at varying strain rates based on the quasi-static and high strain rate stress-strain behaviors. For that, a $( \pm 45)$ symmetric E-glass/polyester composite along with three perpendicular directions were compression tested at quasi-static $\left(1 \times 10^{-3}-1 \times 10^{-2} \mathrm{~s}^{-1}\right)$ and high strain rates $\left(\sim 1000 \mathrm{~s}^{-1}\right)$. The compressive mechanical behavior of the composite was then modeled numerically using MAT_162 of LS-DYNA 971 explicit commercial finite element code. Finally, the operative failure modes of the composite in SHPB and the measured stress waves in SHPB were used to validate the developed models.

\section{Experimental details}

E-glass fiber woven fabric $\left(0.6 \mathrm{~kg} / \mathrm{m}^{2}\right) /$ Crystic PAX 702 polyester composite plates of \pm 45 laminate configuration and $12 \mathrm{~mm}$ in 
thickness were prepared using a vacuum assisted resin transfer molding process. The specimen dimensions are very critical in the SHPB testing. It was previously reported that the length to diameter ratio of cylindrical specimens should be between 0.5 and 2.0 in order to achieve dynamic equilibrium in the specimen during testing $[1,17]$. Cylindrical specimens with length to diameter ratio of one were core-drilled from the prepared plate in longitudinal, long transverse, and through-thickness directions. The core drilled cylindrical specimens (Fig. $1 \mathrm{a}-\mathrm{c}$ ) were quasi-statically tested at quasi-static strain rates, $1 \times 10^{-3}$ and $1 \times 10^{-2} \mathrm{~s}^{-1}$, using a Shimadzu AG-I testing machine. High strain rate compression tests were conducted using a compression SHPB test apparatus. The used SHPB apparatus is made of $20.35 \mathrm{~mm}$ diameter CPM Rex76 ${ }^{\mathrm{TM}}$ steel bar and consisted of a $350 \mathrm{~mm}$ long striker bar, a $3600 \mathrm{~mm}$ incident bar and an $1800 \mathrm{~mm}$ transmitter bar. The strain rate $(\dot{\varepsilon})$, the strain $(\varepsilon)$, and the stress $(\sigma)$ of the tested samples were calculated using the following equations:

$\dot{\varepsilon}(t)=-\frac{2 C_{b}}{L_{s}} \varepsilon_{r}(t)$

$\varepsilon(t)=-\frac{2 C_{b}}{L_{s}} \int_{0}^{t} \varepsilon_{r}(t) d t$

$\sigma(t)=\frac{E_{b} A_{b}}{A_{s}} \varepsilon_{t}(t)$

in which $C_{b}$ is the elastic wave velocity of the bar, $L_{s}$ is the sample length and $A_{s}$ and $A_{b}$ are the sample and bar cross-sectional area, respectively. $\varepsilon_{i}, \varepsilon_{r}$, and $\varepsilon_{t}$ are, respectively, the incident, reflected and transmitted strains measured from strain gages on the bar. The above equations are derived based on the assumption that the forces at sample-bar interfaces are equal. The force equilibrium in the specimens may be checked by the use of dimensionless number $R$ given as [17]

$R=-\frac{2\left(F_{1}-F_{2}\right)}{F_{1}+F_{2}}$

where $F_{1}$ and $F_{2}$ are, respectively, the front and back surface forces on the SHPB sample. The number $R$ is a measure of the deviation from stress equilibrium in the specimen. When the value of $R$ reaches 0 , the stress equilibrium in the sample is reached.

\section{Modeling}

Finite element simulations of the quasi-static and high strain rate compression tests were performed using MAT_162 material model in LS-DYNA 971. In order to simulate quasi-static experiments using explicit LS-DYNA 971 code in a reasonable computa- tional time, mass scaling was applied by defining a positive time step in ${ }^{*}$ CONTROL_TIMESTEP card. The positive time step of 0.002 was used in the quasi-static simulations. The model included three parts: upper moving compression plate, composite specimen and bottom supporting plate. The plates and specimen were modeled using eight-node solid elements. The sizes of the elements used in plates were $2.62 \mathrm{~mm}$ and in the specimen $0.26 \mathrm{~mm}$. The number of elements used in plates and specimen were 33280 and 53760, respectively. An eroding single surface contact was defined between composite layers. Two eroding surface to surface contacts were defined between bottom plate and specimen and between upper plate and specimen. The displacements and rotations of the bottom plate were prevented throughout the simulations and a velocity was defined for the upper plate, the same with the crosshead speed of the experiments.

A full (no symmetry definitions) numerical model was used to simulate SHPB tests. The model had three components: the incident and transmitter bars, each of these $1520 \mathrm{~mm}$ in length and the specimen. For each SHPB test modeled, the output was displayed at several locations within the sample as well as at the location of the strain gages on the incident and transmitter bars of the SHPB set-up. The desired result, then, is that data calculated from the numerical model closely match output from the strain gages on the incident and transmitter bars. If these conditions are met, the model can accurately capture the wave propagation behavior inside the sample and bars. The numerical model can then be further used to determine local conditions at any point within the sample: for example, to predict fracture initiation sites and the local stress gradients. In numerical simulations, shorter bars were used in order to decrease the computational time. It was previously shown that this had the effect of decreasing the transit time between successive waves and shortening the wave duration slightly: however, it did not affect the basic wave-shapes or amplitudes [12]. Trial computations were carried out using full-length bars, but apart from the slightly smaller time window, no significant differences were found and the shorter bars were used in numerical models henceforth. Experimentally measured stress pulse was provided as an input to the face of the incident bar in the simulations and all other boundaries were traction-free. In separate SHPB tests, the stresses in the incident bar as function of time were recorded for two different striker bar velocities. The time window for the striker bar length of $350 \mathrm{~mm}$ is $\sim 150$ microseconds. The recorded incident wave stress as function of time was used input for the simulations of SHPB tests for a certain striker bar velocity. By this way a more accurate stress profile exposed to the specimen could be modeled. The finite element model of a composite specimen between incident and transmitter bars is shown in Fig. 2. The bars and specimen were modeled using

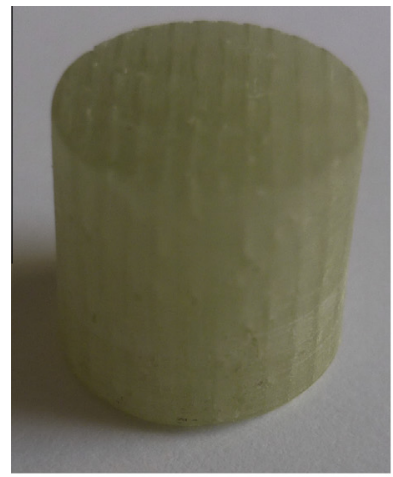

a

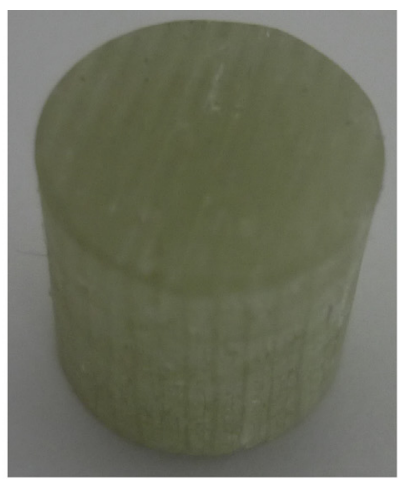

b

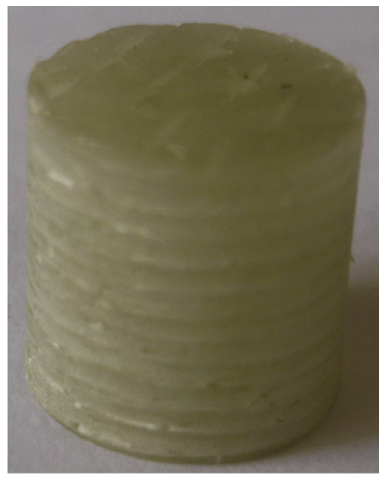

C

Fig. 1. Cylindrical composite samples were cut in (a) longitudinal, (b) long transverse, and (c) through-thickness directions. 


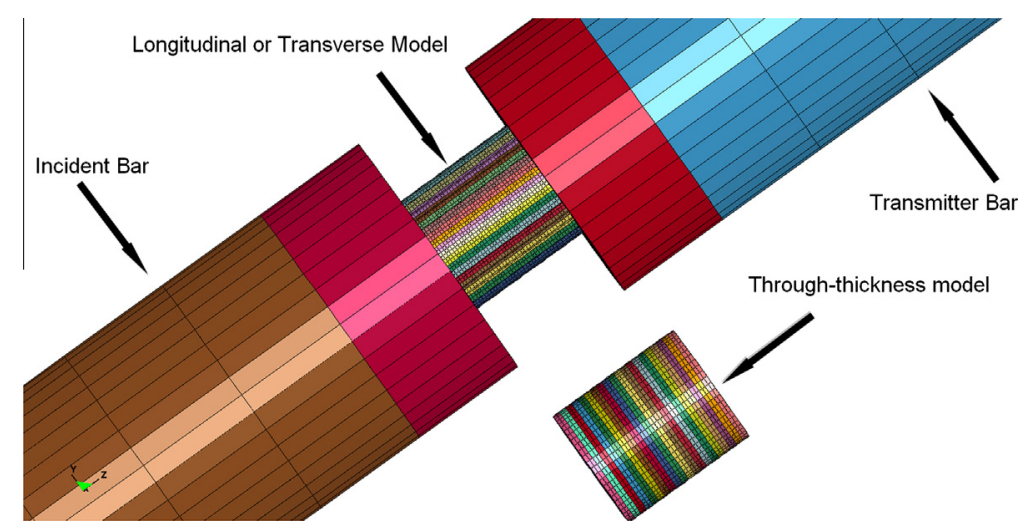

Fig. 2. Finite element model of composite specimens between incident and transmitter bars.

eight-node solid elements. A total of 300 elements were used in the cross-section of the bar, which provided 10 elements across the radius. The length of the bar was modeled using 400 elements. Mesh biasing along the bar axis was applied in order to refine the meshes at the contact interfaces. The number of elements used in bars and specimen were 58800 and 31950, respectively. Eroding single surface contact was defined between the composite layers and both of incident and transmitter bar ends with static and dynamic friction coefficients of 0.3 and 0.2 , respectively. In the model the surfaces of bar ends were assumed to be perfectly flat and the bars were assumed to be deforming elastically during the simulations.

In both quasi-static and high strain rate analyses, MAT_162 progressive failure model was used to analyze the damage progression and delamination in composites. This model is based on the principle of progressive failure of Hashin [18] and damage mechanics of Matzenmiller et al. [19] which controls strain softening behavior after failure. MAT_162 uses nine elastic constants $\left(E_{\mathrm{A}}, E_{\mathrm{B}}, E_{\mathrm{C}}, \vartheta_{\mathrm{BA}}\right.$, $\left.\vartheta_{\mathrm{CA}}, \vartheta_{\mathrm{CB}}, G_{\mathrm{AB}}, G_{\mathrm{BC}}, G_{\mathrm{CA}}\right)$ and ten strength-related parameters $\left(S_{\mathrm{AT}}\right.$, $\left.S_{\mathrm{AC}}, S_{\mathrm{BT}}, S_{\mathrm{BC}}, S_{\mathrm{CT}}, S_{\mathrm{FS}}, S_{\mathrm{FC}}, S_{\mathrm{AB}}, S_{\mathrm{BC}}, S_{\mathrm{CA}}\right)$ to define the yield after elastic deformation. Model uses a material parameter (SFFC) to define residual strength after yield and it simply relates residual strength with maximum stress value. To model matrix and delamination failure, a Coulomb friction angle (PHIC) must be assigned. In the model, a scale factor (S_DELM) is introduced to describe stress concentration at the delamination front. Maximum admissible modulus reduction is defined by a variable, OMGMX. In the model erosion can be in any of three different ways; namely, when axial tensile strain exceeds maximum allowable axial tensile strain (E_LIMT), when compressive relative volume in a failed element is smaller than minimum allowable compressive volume strain (E_CRSH), or when tensile relative volume is greater than limit tensile volume strain (EEXPN). Model uses different failure criteria to cover different damage modes: tensile/shear fiber mode, compression fiber mode, crush mode, perpendicular matrix mode and parallel matrix mode (delamination). MAT_162 is capable of modeling post-damage softening behavior of composites using continuum damage mechanics principles while degrading the material properties. This method of progressive damage uses an exponential damage function with the softening parameter of AM for four different damage modes, e.g., AM1 for fiber damage in the material direction A, AM2 for fiber damage in material direction B, AM3 for fiber crushing, and AM4 for matrix crack and delamination. MAT_162 also accounts for the strain rate effects (CERATE's) in tension, compression and shear which can be used for simulation of high strain rate deformation events.

It was found that when AM1 and AM2 were set to 1.5 and 3.5 respectively, the post-failure behavior of the composite was represented quite well. From the through-thickness compression sample models, damage parameter AM3 was set to 6.5 to represent fiber failure observed in the experiments. The value of AM4 was set to 0.8 in the present analysis. The parameters that also need to be calibrated are out-of-plane fiber strength, matrix shear strength and delamination constant. Interlaminar shear strength and through-thickness tensile strength of the composite were predicted $125 \mathrm{MPa}$ and $70 \mathrm{MPa}$, respectively. Experimental results revealed that the through-thickness tensile strength of the composite was usually lower than the tensile strength of the polyester matrix material. The interlaminar shear stress concentration was studied by Pahr et al. [20] and the stress concentration was reported 1.21. In this study, a value of 1.5 was used for the delamination constant.

In the damage model, the effect of strain-rate on the nonlinear response of composites is modeled by the strain rate dependent function for the strength values as [21]

$$
\left\{S_{r t}\right\}=\left\{S_{0}\right\}\left(1+C_{1} \ln \frac{\dot{\bar{\varepsilon}}}{\dot{\varepsilon}_{0}}\right)
$$

where $C_{1}$ is the strain rate constant for strength properties, $\left\{S_{\mathrm{rt}}\right\}$ are the rate dependent strength values; containing $\left\{S_{\mathrm{AT}} S_{\mathrm{AC}} S_{\mathrm{BT}} S_{\mathrm{BC}} S_{\mathrm{FC}}\right.$ $\left.S_{\mathrm{FS}}\right\}_{\mathrm{T}},\left\{S_{0}\right\}$ are the strength values of $\left\{S_{\mathrm{rt}}\right\}$ at the reference strain rate $\dot{\varepsilon_{0}}$ and $\dot{\bar{\varepsilon}}$ are the longitudinal, transverse and shear strain rate containing $\left\{\dot{\overline{\varepsilon_{a}}} \dot{\overline{\varepsilon_{a}}} \dot{\overline{\varepsilon_{b}}} \dot{\overline{\varepsilon_{b}}} \dot{\overline{\varepsilon_{c}}}\left(\frac{\dot{\varepsilon_{c a}}}{2}+\frac{\dot{\varepsilon_{b c}}}{2}\right)^{1 / 2}\right\}_{\mathrm{T}}$. The rate dependent stiffness is expressed as

$$
\left\{E_{r t}\right\}=\left\{E_{0}\right\}\left(1+C_{i} \ln \frac{\dot{\bar{\varepsilon}}}{\dot{\varepsilon}_{0}}\right) \quad i=2, \cdots, 4
$$

where $\left\{E_{\mathrm{rt}}\right\}$ is the rate dependent stiffness; containing $\left\{E_{\mathrm{A}} E_{\mathrm{B}} E_{\mathrm{C}} G_{\mathrm{AB}}\right.$ $\left.G_{\mathrm{BC}} G_{\mathrm{CA}}\right\}_{T},\left\{E_{0}\right\}$ is the stiffness determined from quasi-static tests, $\dot{\overline{\varepsilon_{a}}}$ longitudinal, transverse, and shear strains containing; $\left\{\dot{\overline{\varepsilon_{a}}} \dot{\overline{\varepsilon_{b}}} \dot{\overline{\varepsilon_{c}}} \frac{\dot{\varepsilon_{a b}}}{\dot{\varepsilon_{b c}}} \dot{\overline{\varepsilon_{c a}}}\right\}_{\mathrm{T}}, C_{2}, C_{3}$ and $C_{4}$ are, respectively, the strain rate constants for the longitudinal, shear and transverse modules. Elastic moduli values along different material directions were obtained by conducting compression quasi-static and SHPB tests. This data were further used for finding out (linear fitting) the strain rate dependency constants. On the experimental data given in the present study, the values of $C_{1}, C_{2}$ and $C_{4}$ were determined, sequentially, $0.024,0.059$ and 0.048 for the tested E-glass/polyester composite. The value of $C_{3}$ was calculated 0.024 from the experimental data given in [22]. During a typical SHPB test, strain rate varies with time, thus an average strain rate was calculated for each test performed. The main objective of introducing strain rate sensitivity parameter in the material model is not monitoring the slight variation of strain rate during the test, instead accurately representing the mechanical behavior within a relatively wide strain rate domain, most likely be 
Table 1

MAT_162 material model properties used in numerical model for E-glass/polyester composite.

\begin{tabular}{|c|c|c|c|}
\hline Density, $\rho\left(\mathrm{kg} \mathrm{m}^{-3}\right)$ & 1850 & Fiber crush, $S_{\mathrm{FC}}(\mathrm{GPa})$ & 0.85 \\
\hline Tensile modulus, $E_{a}, E_{b}, E_{c}(\mathrm{GPa})$ & $24,24,6.66$ & Matrix mode shear strength, $S_{\mathrm{AB}}, S_{\mathrm{BC}}, S_{\mathrm{CA}}(\mathrm{GPa})$ & 0.125 \\
\hline Poisson's ratio, $\vartheta_{a b}, \vartheta_{b c}, \vartheta_{c b}$ & $0.13,0.243,0.0723$ & Residual compressive scale factor, SFFC & 0.2 \\
\hline Shear modulus, $G_{\mathrm{AB}}, G_{\mathrm{BC}}, G_{\mathrm{CA}}(\mathrm{GPa})$ & $2.9,2.14,2.14$ & Friction angle, PHIC (GPa) & 10 \\
\hline In-plane and through thickness tensile strength, $S_{\mathrm{AT}}, S_{\mathrm{BT}}, S_{\mathrm{CT}}(\mathrm{GPa})$ & $0.5,0.5,0.07$ & Delamination, S_DELM & 1.5 \\
\hline Compressive strength, $S_{\mathrm{AC}}, S_{\mathrm{BC}}(\mathrm{GPa})$ & 0.45 & Fiber mode shear strength, $S_{\mathrm{FS}}(\mathrm{GPa})$ & 0.2 \\
\hline Damage Parameter, AM1, AM2, AM3, AM4 & $1.5,3.5,6.5,0.8$ & Strain rate parameter, $C_{1}, C_{2}, C_{3}, C_{4}$ & $0.024,0.059,0.024,0.048$ \\
\hline Erosion parameter, E_LIMT, EEXPN, E_CRSH & $0.025,1.5,0.8$ & & \\
\hline
\end{tabular}

Table 2

Elastic material properties used in numerical model bars and compression plates.

\begin{tabular}{ll}
\hline Density, $\rho\left(\mathrm{kg} \mathrm{m}^{-3}\right)$ & 8255 \\
Young's modulus, $E(\mathrm{GPa})$ & 214 \\
Poisson's ratio, $\vartheta$ & 0.3 \\
\hline
\end{tabular}

seen in typical engineering impact problems such as penetration and perforation of composite armor. Maximum allowable axial tensile strain value of 0.025 was experimentally determined and used in the numerical simulations. The tension test specimens were prepared in accord with ASTM: D3039/D3039M. The remaining two eroding parameters, E_CRSH and EEXPN, were obtained by fine tuning to get the bar responses and damaged shapes of the specimens in all three directions. The MAT_162 material model properties of the composite specimen and elastic material properties of SHPB bars and compression plates are tabulated in Tables 1 and 2, respectively.

\section{Results and discussion}

\subsection{Quasi-static and high strain rate tests}

Fig. 3a-c shows the compression stress-strain curves of the composite in longitudinal, long transverse and through-thickness directions at quasi-static and high strain rates, respectively. It is noted in Fig. 3a that as strain rate increases the failure stress (maximum stress) increases but the failure strain decreases in longitudinal direction. The composite exhibits maximum stresses of $\sim 215 \mathrm{MPa}$ at $10^{-3} \mathrm{~s}^{-1}, \sim 220 \mathrm{MPa}$ at $10^{-2} \mathrm{~s}^{-1}$ and $\sim 295 \mathrm{MPa}$ at $1000 \mathrm{~s}^{-1}$ with corresponding failure strains of $\sim 0.0415, \sim 0.040$ and $\sim 0.0275$, respectively. Previous tests on the similar composite tested in the same direction reported a similar compressive strength of $\sim 300 \mathrm{MPa}$ and compressive failure strain of 0.035 at the strain rate of $1200 \mathrm{~s}^{-1}$ [5]. It is also noted in Fig. 3a-c, the high strain rate stress-strain curves show more nonlinear behavior than quasistatic stress-strain curves. A similar behavior was also detected previously in an S2 glass fiber reinforced polyester composite tested through the similar directions [13]. The delamination of the composite in this direction initiated from the top surface of longitudinal specimens that contact with the upper compression plate for both quasi-static strain rates. The failure at quasi-static strain rates occurred at nearly $45^{\circ}$ to the loading axis. The $45^{\circ}$ inclined crack surface bounded the delaminated top part and relatively undamaged bottom part of specimens. None of the longitudinal specimens were however failed catastrophically at quasi-static strain rates and continued bearing a nearly constant load after failure, corresponding to $50 \%$ of the failure stress (Fig. 3a). The tested longitudinal test specimens were also delaminated in high strain rate tests. Delamination initiated at incident bar-specimen interface and propagated through the specimen. Besides delamination, some minor fragments were observed to separate from the sample.
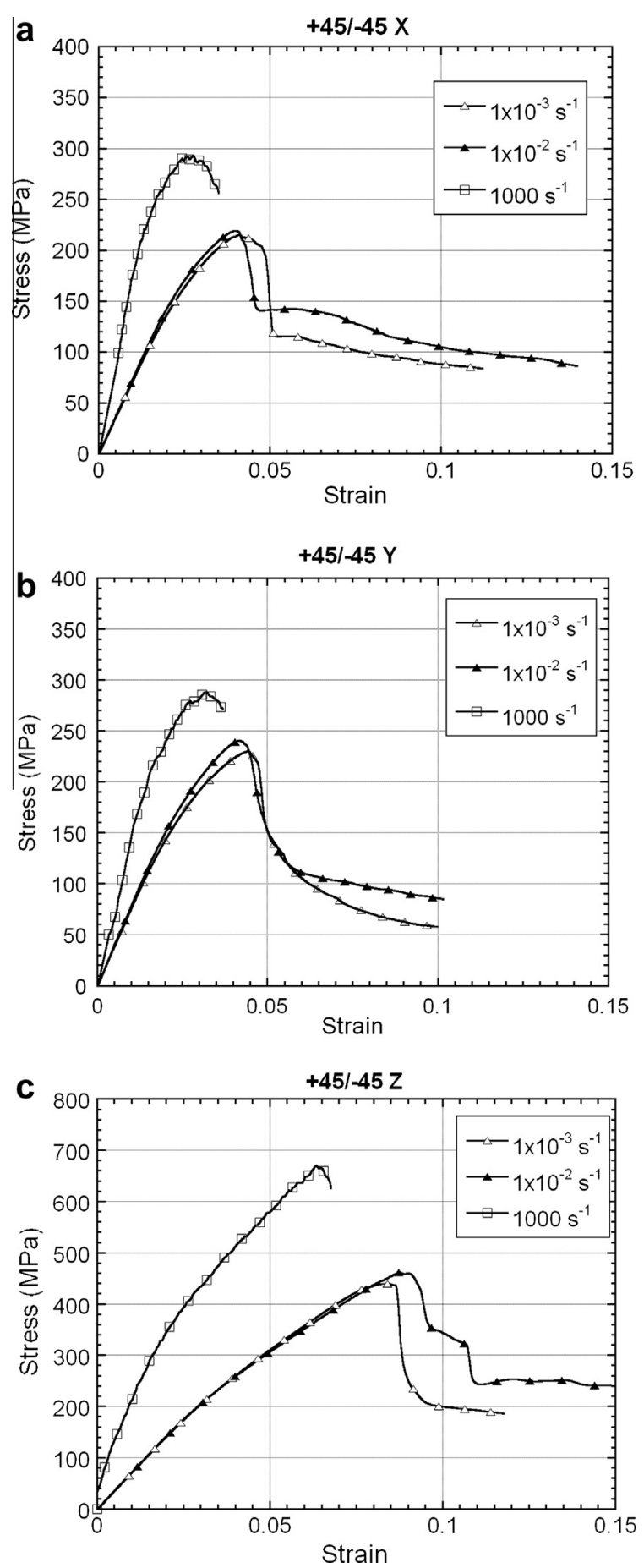

Fig. 3. Quasi-static and high strain rate test results of (a) longitudinal, (b) long transverse, and (c) through-thickness specimens. 


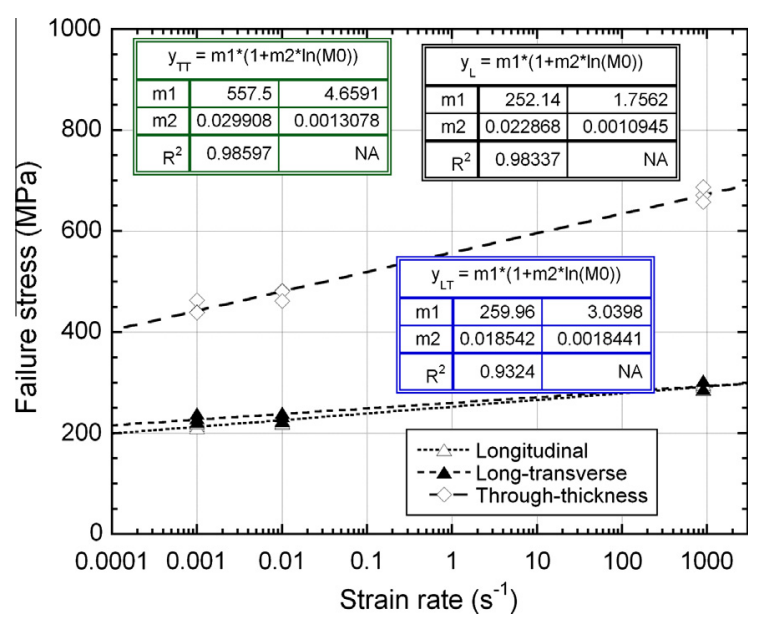

Fig. 4. Strain rate dependency of failure stresses in longitudinal, long transverse, and through-thickness directions.

As with longitudinal direction, the strain rate increases maximum stresses and decreases failure strain of the composite in long-transverse direction as depicted in Fig. 3b. The maximum stress increases from $\sim 230 \mathrm{MPa}$ at $10^{-3} \mathrm{~s}^{-1}$ to $\sim 240 \mathrm{MPa}$ at $10^{-2} \mathrm{~s}^{-1}$ and to $\sim 290 \mathrm{MPa}$ at $1000 \mathrm{~s}^{-1}$. The failure strains were $\sim 0.044$ at $10^{-3} \mathrm{~s}^{-1}, \sim 0.0418$ at $10^{-2} \mathrm{~s}^{-1}$ and $\sim 0.032 \mathrm{MPa}$ at $1000 \mathrm{~s}^{-1}$. Similar to the specimens tested in longitudinal direction; the delamination is the major damage mechanism in specimens tested in long-transverse direction. The delamination initiated from the top surface of long-transverse specimens that contact with upper compression plate for both quasi-static strain rates. Failure at quasi-static strain rates occurred at nearly $45^{\circ}$ to the loading axis. The $45^{\circ}$ inclined crack surface bounded the delaminated top part and relatively undamaged bottom part of the specimens. The delamination damage mode was also observed in the specimens tested at high strain rates. Axial splitting damage mode divided the specimen into two major pieces and some smaller fragments were also separated from the material. Delamination again started at the incident bar-specimen interface. Long-transverse specimens tested quasi-statically had load carrying capability after failure, corresponding to $\sim 50 \%$ of failure stress. Similar results to current work presented in this study have also been found by previous researchers. For example Haque and Ali [15] reported multiple delamination, fiber breakage and extensive cracking resulting in totally shatter in a similar type of composite specimen tested at high strain rate levels. Song et al. [14] also found that the specimen tested in in-plane direction was mostly damaged by delamination between the fibers and resin, indicating low interface strength.

The composite specimens tested through-thickness direction; however, show relatively higher failure stresses and strains (Fig. 3c) at quasi-static and high strain rates as compared with the specimens tested in longitudinal and long-transverse direction. The maximum compressive stress increases from $\sim 440 \mathrm{MPa}$ at $10^{-3} \mathrm{~s}^{-1}$ to $\sim 670 \mathrm{MPa}$ at $1000 \mathrm{~s}^{-1}$. While, the failure strains decrease from $\sim 0.085$ at $10^{-3} \mathrm{~s}^{-1}$ to $\sim 0.065$ at $1000 \mathrm{~s}^{-1}$. The compressive strength and failure strain of a E-glass fiber/epoxy at the strain rate of $1305 \mathrm{~s}^{-1}$ were reported $540 \mathrm{MPa}$ and $\sim 0.05$, respectively [1]. An inclined crack with a $45^{\circ}$ angle bisects through-thickness specimens into two regions. At some of the tests, those parts slide laterally relative to each other and at some tests those parts completely split up (complete axial splitting) and specimens catastrophically failed. Therefore, through-thickness specimens were capable of sustaining loads after failure to some extent (40\% of failure stress) in quasi-static regime. Through-thickness specimens tested at high strain rate were catastrophically failed. A nearly $45^{\circ}$ crack surface was formed and divided the specimen into two pieces with axial splitting damage mode. The piece that was in contact with incident bar was completely crushed. Big fragments of fibers were formed and separated from the material. Somewhat

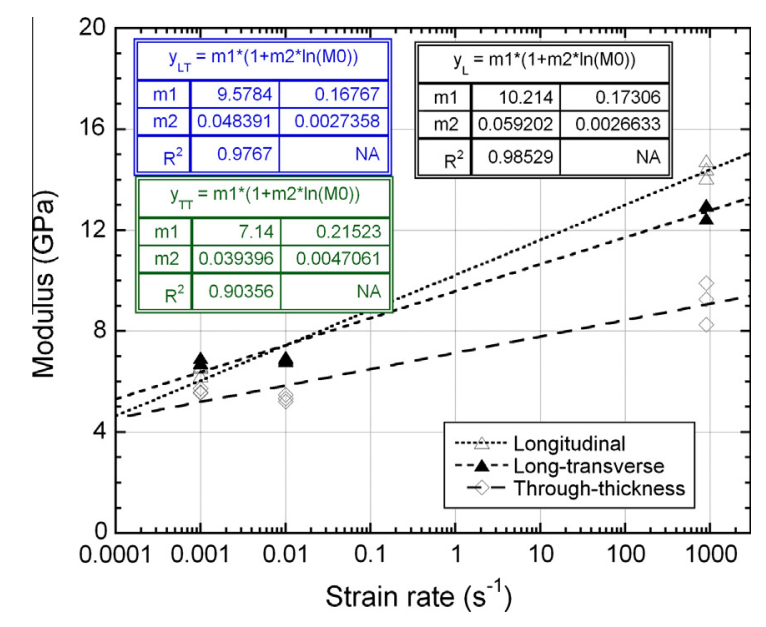

Fig. 5. Strain rate dependency of elastic moduli in longitudinal, long transverse and through-thickness directions.
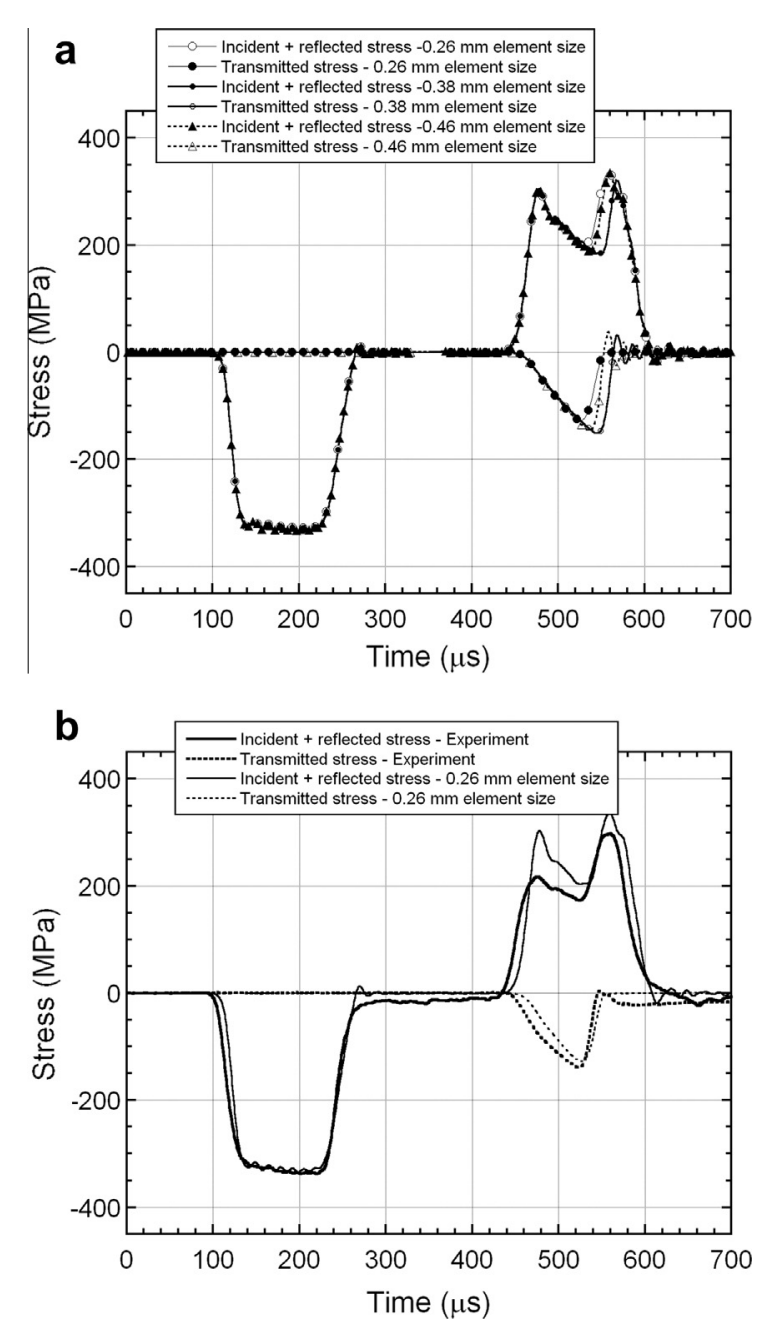

Fig. 6. Mesh sensitivity analysis result of numerical simulation of SHPB experiment. 


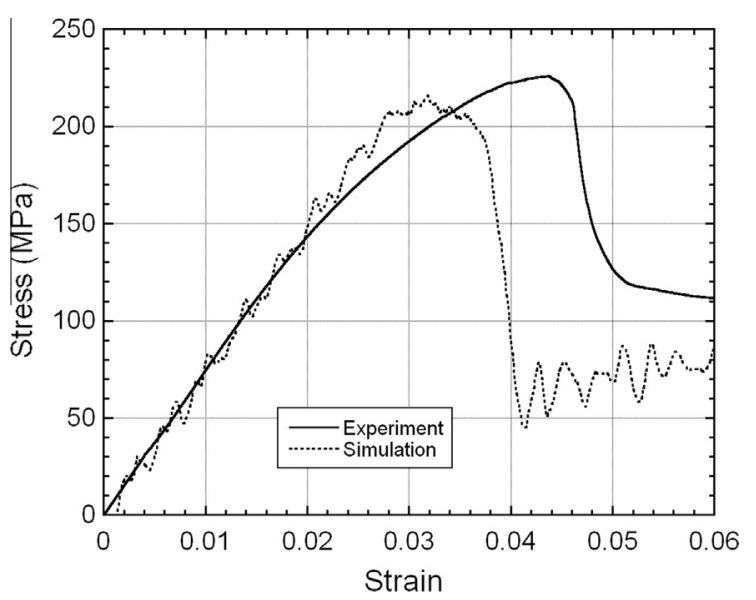

Fig. 7. Comparison of quasi-static experimental and numerical results at $10^{-2} \mathrm{~s}^{-1}$ strain rate.

similar of failure modes in the through-thickness direction were previously observed in the similar composite materials $[23,24]$. Song et al. [14] also showed that both the maximum strain and maximum stress for a similar type of composite specimen tested in the in-plane direction were much less than those along the through-thickness direction due to the different failure modes, which is in accordance with the results of the current study.

Finally, it is likely that the kink band formation (fiber micro buckling) is the incipient failure mode in all tested composite, considering crack surfaces inclined with $45^{\circ}$.

\subsection{Strain rate dependency}

Strain rate dependencies of failure stresses and elastic moduli were determined by fitting the experimental stress and elastic modulus values with the strain rate dependency functions given in Eqs. (5) and (6), respectively. The results of fittings are shown sequentially in Figs. 4 and 5 for failure stresses and elastic moduli. As is seen in Fig. 4, the lowest rate sensitivity of failure stresses is found for the specimens tested in long-transverse direction. The slightly reduced strain rate sensitivity of the stress of an S2 glass fiber reinforced SC15 composite in the in-plane direction than through-thickness direction was previously reported [14]. The slightly increased strain rate sensitivity in the through thickness direction is most likely to due to the higher deformation capability of the composite in this direction. The value of $C_{1}$ is determined

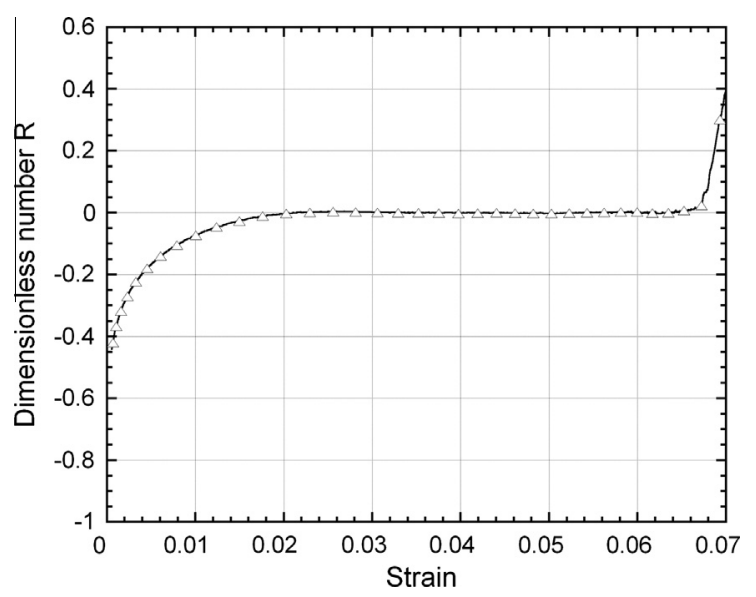

Fig. 9. Dimensionless number R vs. strain calculated from the simulation of high strain rate test of through-thickness specimen.

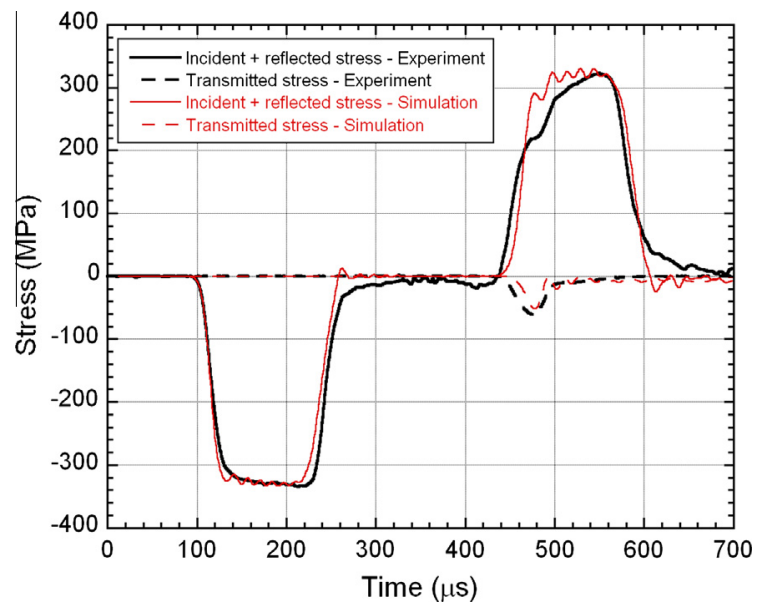

Fig. 10. Comparison of stress vs. time results for a longitudinal specimen.

0.024 by averaging $C_{1}$ values obtained for three different directions. This value is used to simulate strain rate dependent failure stresses of the composite in all three directions. The values of failure stresses are determined from the curve fits as $252 \mathrm{MPa}$ in longitudinal direction, $259 \mathrm{MPa}$ in long-transverse direction and $557 \mathrm{MPa}$ in through-thickness direction at the reference strain rate

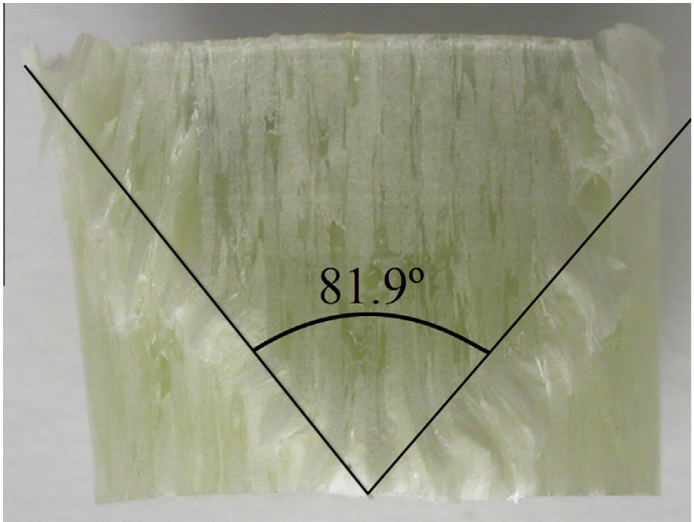

a

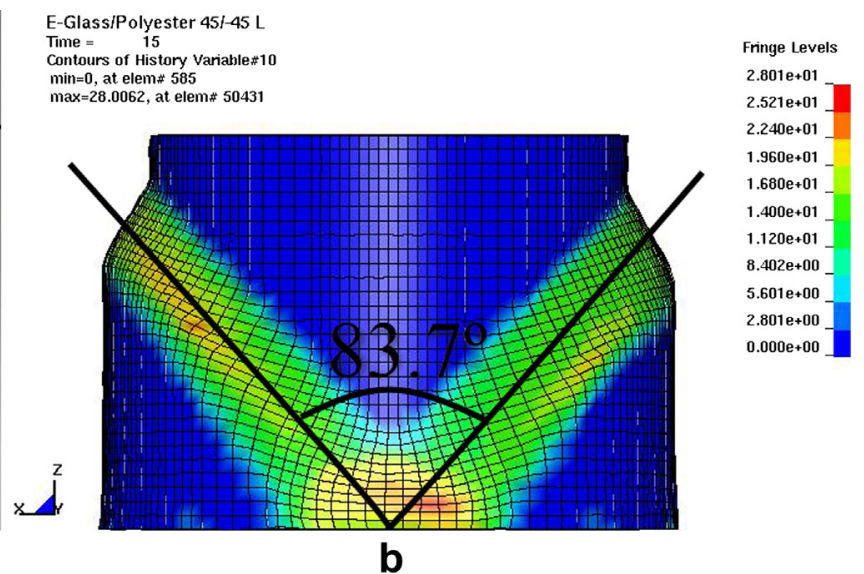

Fig. 8. Failed regions of longitudinal specimen at quasi-static strain rate of $10^{-2} \mathrm{~s}^{-1}$ (a) experiment, (b) simulation with the contours of perpendicular matrix mode. 


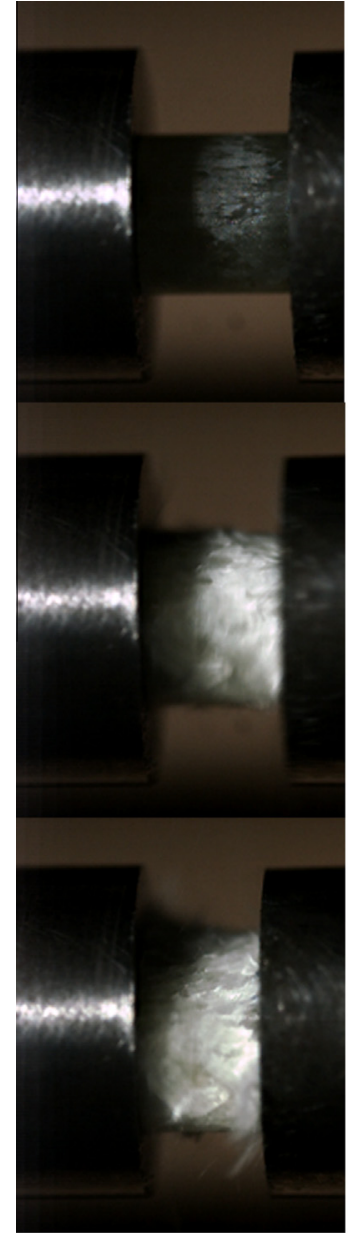

a
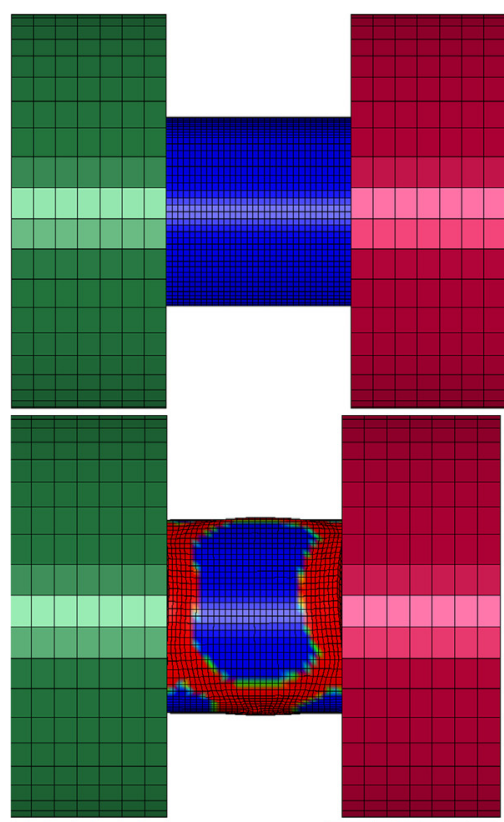

Fringe Levels

$1.000 \mathrm{e}+00$

$9.000 \mathrm{e}-01$

$8.000 \mathrm{e}-01$

$7.000 \mathrm{e}-01$

$6.000 \mathrm{e}-01$

$5.000 \mathrm{e}-01$

$4.000 \mathrm{e}-01$

$3.000 \mathrm{e}-01$

2.000 e- 01

$1.000 \mathrm{e}-01$

$0.000 \mathrm{e}+00$

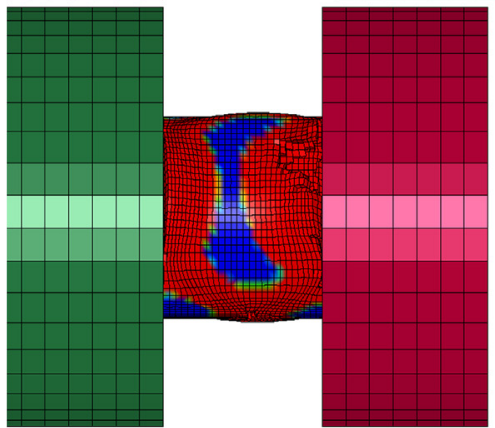

b

Fig. 11. Comparison of damage progression in longitudinal specimen: (a) experiment and (b) simulation in perpendicular matrix mode history variable.

of $1 \mathrm{~s}^{-1}$. The elastic moduli of longitudinal and long-transverse specimens are more rate sensitive than those of through thickness specimens as seen in Fig. 5. The values of $C_{2}$ and $C_{4}$ are sequentially determined to be 0.059 and 0.048 by fitting the elastic moduli of longitudinal and long transverse directions. The elastic moduli are found to be $10.2 \mathrm{GPa}$ in longitudinal, 9.57 GPa in long-transverse and $7.14 \mathrm{GPa}$ in through-thickness directions at the reference strain rate of $1 \mathrm{~s}^{-1}$.

\subsection{Numerical modeling}

In order to investigate the effect of mesh sensitivity, high strain rate testing of a through-thickness specimen was simulated with three different element sizes, $0.46,0.38$ and $0.26 \mathrm{~mm}$. Fig. 6a shows the simulation incident, reflected and transmitted stress variation with time in SHPB testing for the models of three different element sizes. In Fig. 6a, the incident wave is the experimentally input wave in the model. The reflected wave is calculated by selecting elements at the locations of strain gages in real SHPB set-up and calculating the stresses of these elements. Same procedure was applied for the determination of the transmitted wave. It is noted in the same figure that almost no effect of element size on the simulation reflected and transmitted stress values is found, except post-damage softening behavior. The post-damage softening behavior of the composite is better represented by a smaller element size. Therefore, $0.26 \mathrm{~mm}$ element size was chosen for the analyses in this study. Fig. $6 \mathrm{~b}$ shows the variations of the experimental and simulated $(0.26 \mathrm{~mm}$ element size $)$ incident, reflected and transmitted stress with time. In Fig. 6b, since the experimentally measured incident wave oscillations were averaged out, the model and experimental waves show slight differences. The experimental measured reflected and transmitted waves are compared with numerically determined waves of $0.26 \mathrm{~mm}$ element size. Despite the differences between the experimental and simulation reflected stresses, the simulation transmitted stress values approach the experimental transmitted stress values. The model accurately predict the sample stress values while it deviates from experimental strain values, as the reflected wave is used to calculate strain in the specimen, while transmitted wave is used to calculate stress in the specimen.

Quasi-static model was only prepared for testing longitudinal specimens at strain rate $10^{-2} \mathrm{~s}^{-1}$. The experimental and model quasi-static stress-strain curves are shown together in Fig. 7 for comparison. As is seen in the same figure, the model predicts accurately the shape of stress-strain and post-damage softening behavior. However, the model fails to catch the yield strain because experimental stress-strain behavior deviates from linearity in the elastic region. The specimen bears $45 \%$ of the maximum stress after failure in the experiment, while this value is $36 \%$ in the model. This difference simply arises from the fact that an average value of SFFC is chosen for the analysis of the composite in all directions. Fig. 8a and $b$ depicts sequentially the images of the experimental and numerical (with the contours of perpendicular matrix mode history variable) quasi-statically compressed longitudinal sample 


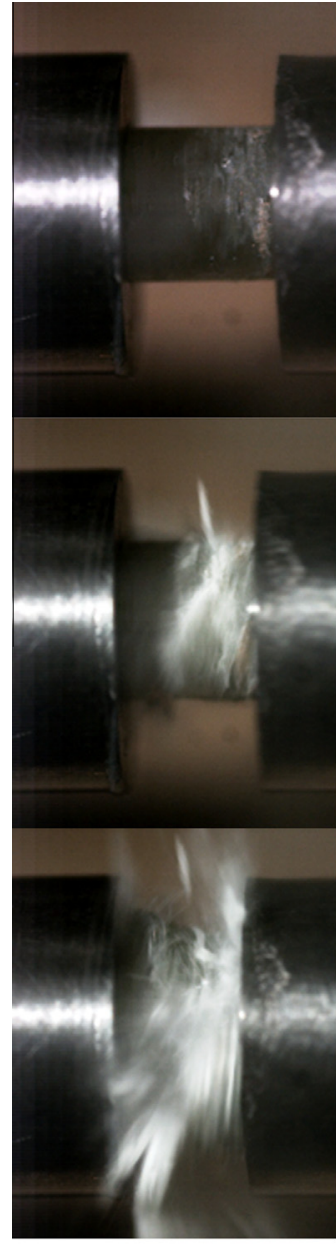

a
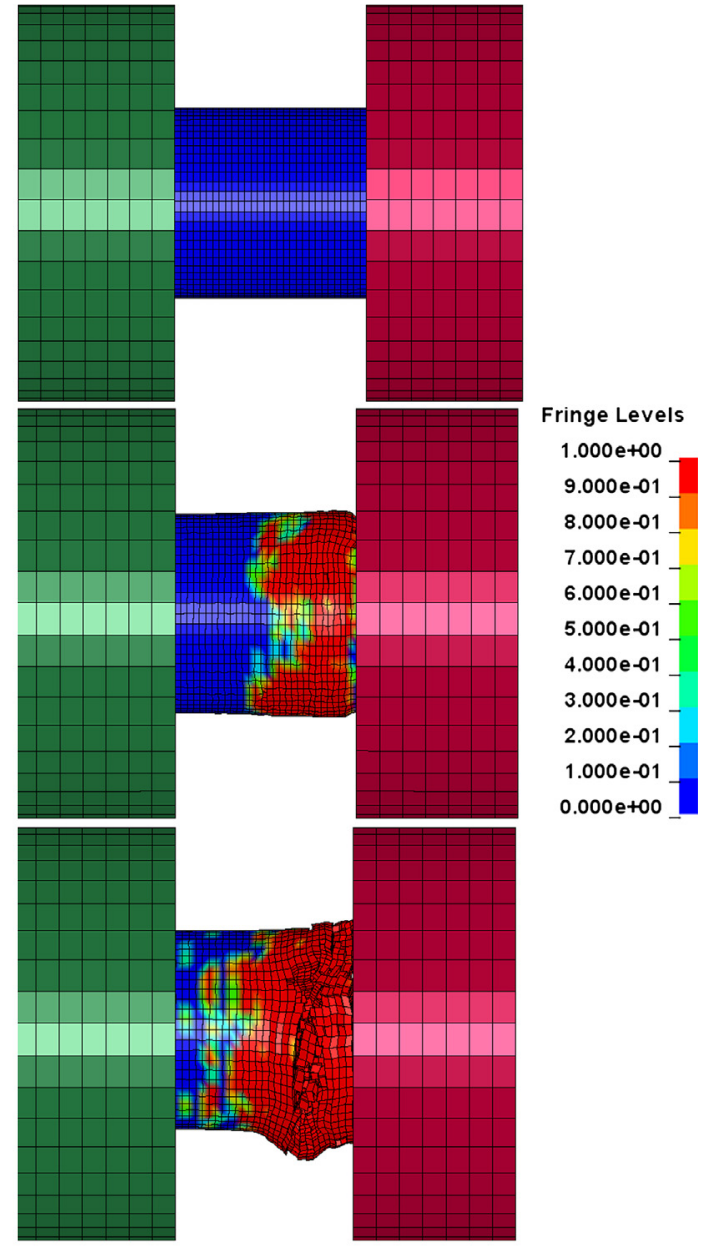

b

Fig. 12. Comparison of damage progression in through-thickness specimen: (a) experiment and (b) simulation in perpendicular matrix mode history variable.

until about 0.06 strain. The post failure analysis of the failed specimens shows both experimentally and numerically that the angle between two interlayer matrix cracks is $\sim 83^{\circ}$. The model catches the damage modes of the composite with an acceptable error level.

Fig. 9 shows the simulation dimensionless number $R$ vs. strain curve of a high strain rate tested through-thickness specimen. At low strains in SHPB test, $R$ is negative and after 0.02 strain it reaches zero. It is further noted that near the specimen failure (strain $>0.06$ ), the value of $R$ tends to deviate from zero. The force equilibrium is reached in the large extent of deformation, between 0.02 and 0.06 .

Fig. 10 shows experimental and numerical SHPB stress-time curves of a longitudinal specimen. Since the long-transverse specimens showed similar stress-strain behavior with longitudinal specimens, the model of long-transverse specimens was not prepared. Again, the numerical and experimental peak transmitted stress values of longitudinal specimens are very much similar, while, the specimen in the model fails earlier than the specimen in the experiment. The numerical model also predicts quite well the post-yield softening behavior and residual compressive stress of the composite.

Fig. 11 shows the experimental high speed camera and simulation deformed pictures of a longitudinal composite specimen tested in SHPB. Results of simulations are given in perpendicular matrix mode history variable in LS-DYNA 971 [21]. Inter-frame time was chosen $46 \mu$ s to catch the damage progression at a total experiment time of $700 \mu \mathrm{s}$. As is seen in Fig. $11(t=92 \mu \mathrm{s})$, the delamination starts at the incident bar specimen interface in the experiment while in the numerical simulation, the damage initiates at both incident bar specimen and transmitted bar specimen interfaces. Some part of the specimen experience relatively lower damage in the experiment, which is verified in numerical simulations. In both experiment and simulation, barreling of the specimen is observed, which is attributed to the friction between bar interfaces and specimen. Fig. 12 shows the experimental high speed camera and simulation deformed pictures of a through thickness composite specimen tested in SHPB. The damage in experiments initiates at the incident bar specimen interface at $46 \mu$ s after the incident wave reaches the specimen interface and a crack nearly $45^{\circ}$ travels across the specimen at $92 \mu \mathrm{s}$. Some layers are completely damaged in the experiment and some small fragments are separated. On the other hand, in simulation, the damage initiates between adjacent layers of the composite near transmitter bar specimen interface.

\section{Conclusions}

The quasi-static and high strain rate deformations of a $( \pm 45)$ symmetric E-glass/Polyester composite were investigated in the in-plane and through thickness directions. The compressive stress-strain behaviors of the composite along both directions 
were found to be strain rate sensitive. The modulus and maximum stress increased with increasing strain rate, while higher strain rate sensitivity was determined in in-plane direction. In the in-plane direction, failure occurred by axial splitting followed by $45^{\circ}$ inclined crack surface formation. In the through thickness direction, failure modes at quasi-static and high strain rates were similar, a nearly $45^{\circ}$ crack surface divided the specimen into two pieces with axial splitting damage mode. Numerical models were developed and successfully predicted the damage initiation and progression as well as the failure modes of the composite at both quasi-static and high strain rates. The damage progression of the composite determined by the high speed camera agreed with that of numerical model.

\section{Acknowledgement}

The authors would like to thank the Scientific and Technical Council of Turkey (TUBITAK) for the Grant \# 106M353.

\section{References}

[1] Naik NK, Venkateswara Rao K, Veerraju C, Ravikumar G. Stress-strain behavior of composites under high strain rate compression along thickness direction: effect of loading condition. Mater Des 2010;31:396-401.

[2] Ochola RO, Marcus K, Nurick GN, Franz T. Mechanical behaviour of glass and carbon fibre reinforced composites at varying strain rates. Compos Struct 2004;63:455-67.

[3] Oguni K, Ravichandran G. Dynamic compressive behavior of unidirectional Eglass/vinylester composites. J Mater Sci 2001;36:831-8.

[4] Shokrieh MM, Omidi MJ. Compressive response of glass-fiber reinforced polymeric composites to increasing compressive strain rates. Compos Struct 2009;89:517-23.

[5] Tarfaoui M, Neme A, Choukri S. Damage kinetics of glass/epoxy composite materials under dynamic compression. J Compos Mater 2009;43:1137-54.

[6] Gary G, Zhao H. Dynamic testing of fibre polymer matrix composite plates under in-plane compression. Compos Part A - Appl Sci 2000;31:835-40.

[7] Majzoobi GH, Fereshteh-Saniee F, Bahrami MA. A tensile impact apparatus for characterization of fibrous composites at high strain rates. J Mater Process Technol 2005;162-163:76-82.
[8] Naik NK, Yernamma P, Thoram NM, Gadipatri R, Kavala VR. High strain rate tensile behavior of woven fabric E-glass/epoxy composite. Polym Test 2010;29:14-22.

[9] Schoßig M, Bierögel C, Grellmann W, Mecklenburg T. Mechanical behavior of glass-fiber reinforced thermoplastic materials under high strain rates. Polym Test 2008;27:893-900.

[10] Kammerer C, Neme A. Plane behaviour at high strain rates of a quasiunidirectional E-glass/polyester composite: application to balistic impacts. Eur J Mech A - Solid 1998;17:461-77.

[11] Kammerer C, Neme A. Plane behavior of an E-glass/polyester composite at high strain rates. Compos Sci Technol 1998;58:717-25.

[12] Tasdemirci A, Hall IW. Numerical and experimental studies of damage generation in a polymer composite material at high strain rates. Polym Test 2006;25:797-806.

[13] Khan AS, Colak OU, Centala P. Compressive failure strengths and modes of woven S2-glass reinforced polyester due to quasi-static and dynamic loading. Int J Plast 2002;18:1337-57.

[14] Song B, Chen W, Weerasooriya T. Quasi-static and dynamic compressive behaviors of a S-2 Glass/SC15 composite. J Compos Mater 2003:37:1723-43.

[15] Haque A, Ali M. High strain rate responses and failure analysis in polymer matrix composites - an experimental and finite element study. J Compos Mater 2005;39:423-50.

[16] Brown K, Brooks R, Warrior N. Numerical simulation of damage in thermoplastic composite materials. In: Fifth European LS-DYNA users conference. Birmingham; 2005.

[17] Ravichandran G, Subhash G. Critical appraisal of limiting strain rates for compression testing of ceramics in a split Hopkinson pressure bar. J Am Ceram Soc 1994;77:263-7.

[18] Hashin Z. Failure criteria for unidirectional fiber composites. J Appl Mech 1980;47:329-34.

[19] Matzenmiller A, Lubliner J, Taylor RL. A constitutive model for anisotropic damage in fiber-composites. Mech. Mater. 1995;20:125-52.

[20] Pahr DH, Rammerstorfer FG, Rosenkranz P, Humer K, Weber HW. A study of short-beam-shear and double-lap-shear specimens of glass fabric/epoxy composites. Compos Part B - Eng 2002;33:125-32.

[21] LSTC. LS-DYNA: Keyword User's Manual. Livermore Software Technology Corporation; 2007.

[22] Naik NK, Asmelash A, Kavala VR, Ch V. Interlaminar shear properties of polymer matrix composites: strain rate effect. Mech Mater 2007;39:1043-52.

[23] Akil Ö, Yıldırım U, Güden M, Hall IW. Effect of strain rate on the compression behaviour of a woven fabric S2-glass fiber reinforced vinyl ester composite. Polym Test 2003;22:883-7.

[24] Guden M, Yildirim U, Hall IW. Effect of strain rate on the compression behavior of a woven glass fiber/SC-15 composite. Polym Test 2004;23:719-25. 